(i-COME'20)

INTERNATIONAL CONFERENCE ON COMMUNICATION AND MEDIA 2020

\title{
MEDICAL SOCIAL WELFARE SERVICES AND ROLE OF HEALTH COMMUNICATION IN KANO, NIGERIA
}

\author{
Adamu Tijjani Yahya (a)*, Aminu Zubairu Surajo (b), Abdulkadir Shitu Umar (c) \\ *Corresponding author
}

(a) Department of Social Development, School of Rural Technology and Entrepreneurship Development, Rano, Kano State Polytechnic, Nigeria. a.tyahya@gmail.com

(b) Department of Social Development, School of Rural Technology and Entrepreneurship Development, Rano, Kano State Polytechnic, Nigeria. aminuzubairus@gmail.com

(c) Department of Social Development, School of Rural Technology and Entrepreneurship Development, Rano, Kano State Polytechnic, Nigeria. abdulkadirumar52@gmail.com

\begin{abstract}
The provision of medical social welfare services is an important social agenda for the well-being of the indigent patients, particularly the poor, aged and the destitute who are the victims of social deprivation, anxiety and emotional trauma. Alternatively, the global era of Information and Communication Technology (ICT) has aided in promoting health related issues concerning the services provided by the Medical Social Welfare Units through social media, websites, radio and television programmes and access to mobile network services. The paper focuses on the impact of utilization of health communication gadgets in providing medical social welfare support services. The study utilizes survey research design which involved the registered indigent patients and staff of three facility hospitals in Kano, namely: Aminu Kano Teaching Hospital, National Orthopaedic Hospital and Murtala Mohammed Specialist Hospital. Structured questionnaires were administered to the respondents and a total of 172 respondents was utilised for the study. However, stratified random sampling was used to select the respondents. The data were subjected to simple frequency count and percentage. The findings revealed that, access to communication have promoted the spread of information on health-related issues among the indigent patients. The study revealed that support services were provided in form of financial and psycho-social support, counselling services etc. The impact of health communication facilities includes awareness to the patients and networking with the service providers. The paper recommends the upgrading of communication accessibility and improving the staff welfare for effective service delivery in order to break the barriers of Health communication.
\end{abstract}




\section{Introduction}

The provision of Medical Social Welfare Services to the individuals, who could not afford the basic social needs, let alone medical care at the various levels of their illnesses, is not a new development; this is as a result of widespread poverty in the society. Perhaps, victims of poverty become destitute who are socially deprived of certain human rights, experience anxiety and severe state of trauma often leading to death. The Medical Social Welfare Units play an important role in various care or welfare issues affecting the patients, which the Physicians, Nurses and other supporting medical staff might not be able to play. The various aspects of intervention in the profession cover the financial, psychosocial, counselling and rehabilitation among others, to promote the social wellbeing of the indigent patients and groups in the society. Health communication interventions have been successfully used for many years by non-profit organizations, the commercial sector, and others to advance public, corporate, or productrelated goals in relation to health. As many authors have noted, health communication draws from numerous disciplines, including health education, mass communication, social marketing, psychology, anthropology, and sociology (Bernhardt, 2004; Institute of Medicine, 2003; World Health Organization, 2003). It relies on different communication activities or action areas, which include interpersonal communications, public relations, public advocacy, community mobilization, and professional communications (World Health Organization, 2003; Bernhardt, 2004).

One of the key objectives of health communication is to influence individuals and communities. The goal is admirable since health communication aims to improve health outcomes by sharing healthrelated information. In fact, the Centres for Disease Control and Prevention (CDC) define health communication as "the study and use of communication strategies to inform and influence individual and community decisions that enhance health" (U.S. Department of Health and Human Services, 2005).

Therefore, Kano State has been benefitting the health communication accesses which greatly promote awareness of the Medical Social Welfare Services available on health needs especially among the indigent patients. The support services being provided to the indigent patients could not be accessed generally rather available only at the facility hospitals as such made the services inadequate. Perhaps, beneficiaries of the support services appear very little considering the population of the metropolitan comprising individuals from various communities residing in Kano. Nevertheless, the impact of the support services on the wellbeing of the beneficiaries in Kano represent the desire to further enhance the health communication facilities to maintain the provision of the support services despite challenges associated with access and delivery of the services to indigent patients.

It is against this background that the paper will examine the role of health communication in promoting the Medical Social Welfare Services offered to indigent Patients in terms of how the services supported their social well-being from a holistic perspective with the aid of Information Communication Technology (ICT). 


\section{Problem Statement}

Indigent patients and their relatives experience many challenges in meeting up with the hospital demands. Some of these demands are connected to financial commitments; clients seeking psychosocial therapy; counselling, and rehabilitation services; networking with other service providers, and a host of others, which have become more difficult to attain whenever patients are registered. Individuals and groups fall victims of becoming disadvantaged in accessing the social welfare services in the hospital settings.

Similarly, many health related problems may result from lack of communication strategies to inform and influence individual and community decisions that enhance health coupled with economic conditions or failure in business, family disintegration or unequal sharing of resources for members as well as other situations connected to failure in meeting life expectations and other ambitions.

\section{Research Questions}

This study answered the following research questions:

- What types of Information and Communication Technologies do you have access to in your area?

- What are the contributions of health communication in promoting Medical Social Welfare Services in Kano State?

- What impact does the health communication have on the Indigent Patients in Kano State?

- To what extent does the health communication gadget promote the social well-being of the Indigent Patients in Kano State?

\section{Purpose of the Study}

The purpose of the study includes:

- To find out the available Information and Communication Technological accesses to Indigent Patients in Kano State.

- To find out the contribution of health communication in promoting Medical Social Welfare Services in Kano State.

- To examine the impact of the health communication for the indigent patients in Kano State.

- To find out the extent to which the health communication gadgets promote the social well-being of the Indigent Patients in Kano State.

\section{Research Methods}

A survey research design was used as an appropriate method for this study. The population of the study was categorized into two namely the indigent patients of tertiary health facilities and staff of the Medical Social Welfare Units of these health facilities in Kano State. Therefore, based on the staff and patients registers of the three facility hospitals, the total population of the registered patients were one 
hundred and fifty-six (156), and which included both in-patients and out-patients respectively, while the Staff were thirty-six (36) as described in the Table 1.

Table 1. Number of Indigent Patients and Staff in the Population

\begin{tabular}{cccc}
\hline $\mathbf{S} / \mathbf{N}$ & Facility Health & Number of Patients & Number of Staff \\
\hline 1. & $\begin{array}{c}\text { Aminu Kano Teaching } \\
\text { Hospital }\end{array}$ & 62 & 18 \\
2. & $\begin{array}{c}\text { National Orthopaedic } \\
\text { Hospital Dala } \\
\text { Murtala Mohammed } \\
\text { Specialist Hospital } \\
\text { TOTAL }\end{array}$ & 74 & 10 \\
& 20 & 08 \\
& 156 & 36 \\
\hline
\end{tabular}

The sample size of the study was drawn from the one hundred and ninety-two (192) patients and staff of the selected hospitals in Kano metropolis, viz. Aminu Kano Teaching Hospital, National Orthopaedic Hospital, Dala, and the Murtala Mohammed Specialist Hospital. While thirty-six (36) staff of the Medical Social Welfare Units were selected using a purposive sampling technique, making a total sample of one hundred and seventy-two (172) subjects for the study.

The study employed the use of questionnaire for the patients and an Interview schedule for the Staff of the Medical Social Welfare Units, as the instruments for data collection. The self-developed questionnaire, known as 'Questionnaire for patients of Medical Social Welfare Units' (QPMSWU), was used, while Staff were interviewed using an interview schedule.

\section{Findings}

The role played by the Health Communication in promoting Medical Social Welfare Services among the Indigent Patients who are considered the lower class cannot be over emphasized most especially in the ICTs era of global communication opportunities. It was observed that access to various Communication services by the Indigent Patients in the Kano Metropolis have widen the chances of breaking through the awareness on the available services rendered by the Medical Social Welfare Units of the tertiary Hospital settings, these include the counselling services, psycho-social support and other family re-integrative services through mobile phone messages, E-mails or website information access, internet subscription, Radio and Television Health educative programmes. As argued by Ajayi (2003), that ICTs have taken over the control of everything that is done as a ready tool in all spheres of life. Accordingly, eighty-seven (87) respondents (64\%) of the One hundred and thirty-six (136) questionnaires distributed ascertained that availability of the access to ICTs increased the level of awareness of the Medical Social Welfare Services among the Indigent Patients in Kano State. Similarly, twenty-three (23) Staff Sixty-Four (64\%) of the Thirty-six (36) selected from the three tertiary Hospitals in the Kano Metropolis supported the role of the access to ICTs among the Indigent Patients in increasing the level of awareness of their support services through the available Health Communication strategies.

Furthermore, on the contribution of Health Communication in the spread of Medical Social welfare Services among the Indigent Patients, Seventy-two (72) respondents (53\%) equally supported by 
Twenty-six (26) Interviewed Staff (72.2\%) were of the view that Health Communication with the aid of bringing updates on the activities of the Nigeria Association of Social Workers (NASOW) which is the mother umbrella of the Association of Medical Social Workers of Nigeria (AMSWON) on the opportunities Indigent Patients could drive. Indigent Patients as noted from the study do utilize the use of mobile phones to create groups through the WhatsApp application and communicate by passing information about the Medical Social Welfare Services, especially outpatients who have already benefited the services and still had contact with the Unit.

On examining the impacts of the Health Communication on Indigent Patients, seventy-one (71) respondents $(52.2 \%)$ responded positively and re-affirmed on the impact through strategizing channels of the fastest and wide coverage of information within the short period of time to a large group of people. This was due to the Communication facilities provided in promoting the services of the Medical Social Welfare in comparison with their counterparts in other developed Communities visa-viz the needs assessment of their Clients by sharing and exchange of ideas for better service delivery. Gates (1999) reported that Intra- and Inter Organizational networks in some advanced Countries function like a digital neural system of the Organization. Impliedly, Communication for Health purposes shifted from the largely manual or physical documentary method to digital Communication. On the same vein, twenty-five (25) Staff interviewed (69.4\%) supported the view and acknowledged the effort of the Hospitals Management by providing avenue for networking the Units with an advanced system of Communication to assess their Clients' needs and recommends appropriate intervention or suggest for a reliable service provider.

Finally, the study identified the extent to which the Health Communication gadgets in promoting the Social Wellbeing of the Indigent Patients considering the Seventy-five (75) respondents (55.1\%) who expressed satisfaction on the effectiveness of the Health Communication gadgets in promoting the social wellbeing of the Indigent Patients in Kano State despite some challenges which include the cost of service charges by the Network service providers. Similarly, thirty-three (33) Staff interviewed (91.7\%) justified the views of the respondents considering their level of accepting the support Services being provided by the Medical Social Welfare Units through the various Health Communication linkages.

The promotion of the Medical Social Welfare Services to the Indigent patients in Kano State fell under the auspices of an effective Communication strategy championed by the Health articulated programmes and Personnel as the holistic Social Welfare doctrine, pronounced by Midgley (1997), that "this is a situation of human well-being that exists when social problems are managed; when human needs are met and when social opportunities are maximized. By this, social welfare can exist at different levels and for associations, groups, communities, families, societies, and organizations. Therefore, in order to ensure a state of good welfare, social needs needed to be met.

\section{Conclusion}

The significant role played by the Health Communication is highly appreciative considering its contribution in creating awareness, motivation and promoting the Medical Social Welfare Services particularly the Indigent Patients in Kano State and beyond. Greater success in achieving the goals of achieving good health among all classes of Citizens irrespective of their social background in any country 
relies solely on the available Information and Communication Technologies (ICTs) governed by sound regulatory policy to checkmate the activities of the Network service Providers in order to ensure easy and affordable access for effective service delivery of the Medical Social Welfare Support and intervention. Attaining such level of global Communication could make a greater impact on the Healthcare provision in the Third-World Countries including Nigeria to address the increasing rate of the poor class Citizens seeking Medical Support thereby falling victims of inaccessible Health Patients.

The support and recognition of the services offered by the Medical Social Welfare Units' personnel were, therefore, necessary to cover all types of distress suffered by Indigent patients. Moreover, the support was not only limited to the authorities concerned, but also a collective responsibility of every other member, through the realization of his/her impact on humanity and stability of patients. Employing the intervention of the Medical Social Welfare Units' professionals in the hospitals in Kano State had surely addressed a number of critical problems for indigent patients, ranging from family disorganization; people falling victims of critical states of health- related illnesses, and other emotional disturbances.

\section{References}

Ajayi, O. G. (2003, October). NITDA and ICT in Nigeria. Paper presented at the 2003 Round Table on Developing Countries Access to Scientific Knowledge, Trieste, Italy. September 11, 2007, http://ejds.org/meeting2003/ictp/papers/Ajayi.pdf

Bernhardt, J. M. (2004). Online Paediatric Information Seeking among Mothers of Young Children: Result from Qualitative Study using Focus Groups. Journal of Medical Internet Research 1(1) pp. 230-238.

Gates, W. H. (1999). Business at the speed of thought. New York: Warner Books.

Institute of Medicine (2003). Health Profession Education: A Bridge to Quality. Washington DC, National Academic Press.

Midgley, J. (1997). Social Welfare in Global Context, Saga Publications.

U S Department of Health and Human Services (2005). A need for Global Health Leadership in Preparedness and Health Diplomacy.

World Health Organization. (2003). The world health report 2003: shaping the future. World Health Organization. 